\title{
ANÁLISE TÉCNICA DA PRODUÇÃO DE FOTOGRAFIAS DE CULINÁRIA
}

\author{
Rodrigo Pereira Carvalho' e Jari Vieira $^{2}$
}

\begin{abstract}
Resumo
Preparar uma produção fotográfica de culinária não é tarefa fácil. O olhar do fotógrafo e o bom sabor do prato não garantem uma imagem de qualidade. Várias são as situações em que o prato será fotografado como, por exemplo, num restaurante, numa exposição de festival de culinária e não num estúdio fotográfico profissional onde todos os objetos da cena já estão nos seus devidos lugares. No intuito de mostrar algumas fotografias de alimentos capturadas em diferentes situações e ambientes, o presente trabalho tem como objetivo analisar a produção de dez fotografias de culinária. Para isso, foram utilizados como referencial teórico a Teoria das Cores, composição, configurações especificas da câmera para se obter o resultado desejado e harmonização da imagem. Foram utilizadas dez fotografias de alimentos, cinco delas consideradas de boa qualidade pelo o autor e cinco consideradas de qualidade inferior. Através dessa análise, foi possível concluir que para que se consiga uma boa fotografia de alimentos é preciso dentre outras coisas, quatro elementos básicos: uma boa preparação da luz, um cenário harmonioso, equipamentos adequados e uma boa apresentação dos alimentos.
\end{abstract}

Palavras-chaves: Análise técnica, Fotografia, Culinária, Gastronomia

\section{TECHNICAL ANALYSIS OF PRODUCTION FOOD PHOTOS}

\begin{abstract}
To prepare a photographic production of food is no easy task. The eye of the photographer and the good taste of the dish does not guarantee a quality image. There are several situations in which the plate will be photographed, for example, a restaurant, an exhibition of festival food and not a professional photographic studio where all the objects in the scene are already in place. In order to show some pictures of food caught in different situations and environments, this study aims to analyze the production of ten photographs of cooking. For this they were used as theoretical framework the theory of colors, composition, specific camera settings to obtain the desired result and image matching. We used ten photographs of food, five of whom were considered good quality for the author five considered inferior. Through this analysis, we concluded that in order to gain a good picture of food is necessary among other things, four basic elements: a good preparation of light, a harmonious setting, appropriate equipment and a good presentation of food.
\end{abstract}

Key-words: Technical analysis, Photography, Cooking, Gastronomy

\section{Introdução}

Preparar uma produção fotográfica de culinária não é tarefa fácil. O olhar do fotógrafo e o bom sabor do prato não garantem uma imagem de qualidade. Várias são as situações em que o prato será fotografado como, por exemplo, num restaurante, numa exposição de festival de culinária onde o prato pode estar exposto a iluminações alheias que podem interferir na iluminação desejada. Já num estúdio fotográfico profissional, torna-se mais fácil, pois é possível controlar precisamente as fontes de luz incidentes no prato a ser fotografado.

${ }^{1}$ Graduado em Comunicação Social - Habilitação em Publicidade e Propaganda pela Estácio FIC-Ceará.

${ }^{2}$ Professor de Comunicação Social da Estácio FIC-Ceará. 
Para Freeman (2001), a crescente procura do mercado gastronômico por fotografias de boa qualidade transformou a fotografia de comidas e bebidas numa arte

especializada e exigente. É preciso ter uma combinação de técnicas específicas de natureza morta e conhecimentos de arte-culinária.

Para o autor, todas as comidas e as bebidas podem ser consideradas como se fossem quaisquer naturezasmortas, mas a permanente necessidade de que fiquem atraentes quando ilustram uma receita ou anunciam um produto alimentar habituou-nos a esperar que, numa fotografia, os alimentos tenham um aspecto apetitoso, quase artificial. O principal problema de conseguir uma fotografia de culinária atraente é achar uma forma de manter os ingredientes fundamentais de um prato: o sabor e o aroma. Para isso, Freeman (2001) afirma que é essencial a habilidade do bom fotógrafo em empregar um misto de ambiente, preparação, cuidados, iluminação adequada e cor para sugerir ao observador os ingredientes que faltam.

A preparação da comida é, talvez, a parte mais difícil da fotografia de culinária. É preciso muita atenção e cuidado do chefe de cozinha na montagem do prato, pois cabe a ele preparar um prato visualmente atraente. O fotógrafo também precisa estar atento na escolha dos alimentos, pois estes devem parecer sempre perfeitos. Freeman (2001) ressalta que "existem vários truques para que os alimentos tenham um aspecto apetitoso, embora a ética profissional e a publicitária limitem os substantivos utilizáveis para o trabalho profissional. Eis alguns dos truques mais vulgares: utilizar o fumo do tabaco em vez de vapor; pintar as salsichas e outros comestíveis com glicerina para lhes dar um brilho atraente e impedir que sequem; verter sobre a fruta sumo de limão para que não adquira um tom acastanhado; utilizar espuma para a barba em vez de natas; pulverizar as saladas e as verduras com gotículas de água com um pulverizados de jardim, para terem aspecto fresco."

A fotografia é uma forma de expressão visual, uma linguagem que possui diversas formas e aplicações. Especificamente à fotografia de alimentos, ela deve mexer com a imaginação de quem vê a foto, despertando a vontade de provar o produto.

Uma boa fotografia de alimento vai conseguir transmitir a textura, o aroma, o sabor do prato. Para transmitir essas sensações e assim garantir uma imagem de qualidade, apenas o olhar do fotógrafo e o bom sabor dos alimentos não são suficientes. Portanto, este trabalho tem como justificativa contribuir com o maior conhecimento sobre técnicas de produção e particularidades da fotografia de culinária para fotógrafos iniciantes que querem conhecer e talvez ingressar nessa área da fotografia. No intuito de mostrar algumas fotografias de alimentos capturadas em diferentes situações e ambientes, o presente trabalho tem como objetivo analisar a produção de quatro fotografias de culinária. 


\section{Referencial Teórico}

Nesta etapa foram utilizados os termos e conceitos utilizados com frequência no desenvolvimento do trabalho para facilitar o entendimento do leitor. A Luz é o elemento básico da fotografia. De fato, qualquer fotografia capta o efeito da luz sobre os objetos, se tomadas em luz natural ou em brilho de luz incandescente. Folts (2007) assegura que "o uso eficiente da luz pode ser a diferença entre uma fotografia medíocre e uma grandiosa." (pág. 161). Segundo o mesmo autor, a qualidade de luz é influenciada pela sua "intensidade (a quantidade de luz que alcança o objeto), contraste (a diferença nos níveis de iluminação entre áreas do objeto totalmente iluminadas e áreas indiretamente iluminadas), especularidade (a luz pode ser concentrada e muito penetrante ou, no outro extremo, muito suave e difusa), direção (o ângulo por meio do qual a luz atinge o objeto. Ela afeta o modo que textura e forma são mostradas na fotografia) e cor (a luz pode ser fria-azulada ou quente-amarelo/avermelhado)." (pag. 161-164).

Para Folts (2007), os tipos de luz mais comuns são: "natural (é a luz do sol, pode ter muitas formas, desde a luz suave, difusa, de um dia nublado, à luz dura e contrastada direta do sol), disponível (é a luz encontrada no local de sua fotografia, geralmente interna para distinguir da luz natural do sol, mas também externa, noturna, quando a luz do sol dá lugar a outras fontes de luz externas) e artificial (refere-se à luz adicionada além da luz existente na cena, pode ser simples como um flash ou complexa como as luzes de estúdio).” P.165.

$\mathrm{Na}$ fotografia de culinária, uma iluminação cuidadosa tem importância especial porque o fotógrafo, com uma manipulação hábil da textura, da cor e do ambiente, pode sugerir o sabor e o aroma. Folts (2007) diz que é corrente colocar a luz a baixa altura, sobre os alimentos, para realçar as texturas. Uma luz não totalmente de frente para a foto câmera, por cima e um pouco por detrás da zona da fotografia, é a ideal." Folts (2007) diz: "nas fotografias comercias sobre comidas, a iluminação é, em geral, conservadora, porque as pessoas tem expectativas muito concretas sobre o aspecto que os alimentos devem ter; o fotografo só pode dar aos alimentos um aspecto apetecível se se ajustar a estas expectativas. Uma iluminação suave, difusa, mais ou menos por cima, é talvez a mais habitual e tradicional, caracterizando bem esse tipo de fotografias" P.231.

Um fotógrafo que compreende como funciona o olho a lente e o espectro de cores consegue fazer o uso pleno de luz na fotografia. Issac Newton (1642-1727), físico inglês, fez experiências com a luz e tornou-se responsável pela primeira descrição científica neste do fenômeno cromático - a Teoria das Cores. Arnheim apud Guimarães, (2000) ao explicar sobre as funções exercidas pela cor, ele afirma que é a cor é a mais eficiente dimensão de discriminação e demonstra um total poder de expressão. Kandinsky (data) vai mais além, ele diz que: “A cor provoca uma vibração psíquica. Seu efeito superficial é apenas, em suma, o caminho que lhe serve para atingir a alma".

Na fotografia de culinária você não deve mostrar a verdadeira aparência do alimento e sim transmitir a sensação de quando saboreia aquele prato e para conseguir isso, o fotógrafo precisa trabalhar muito bem com vários elementos, principalmente com a luz e a harmonia das cores. "A força expressiva da cor, quando usada numa composição, está subordinada a uma série de regras, que podem alterar aumentar ou moderar o seu poder" 
(FARINA, 1986). Farina (1986) quando se refere a cor, ele chama de harmônica a combinação entre cores quando estas possuem uma parte básica da cor comum a todas.

Tecnicamente, harmonia cromática é o resultado do equilíbrio entre cor dominante (que possui a maior extensão na composição), a cor tônica (coloração vibrante que dá tom ao conjunto) e a cor intermediária (meio termo entre a dominante e a tônica). Segundo Bergstrong (2009), o círculo cromático (Figura 01) é um instrumento que ajuda a decidir qual cor devemos usar. Há basicamente quatro tipos de combinação de cores: cores combinantes ou análogas (combinação de duas cores do quadrante superior direito, por exemplo elas formam um todo harmonioso pois combinaram entre seus tons); cores próximas ou primárias ( combinação de duas ou mais cores de quadrantes próximos que obterá cores que juntas formam um contraste vital); cores opostas ou complementares (combinação de cores de quadrantes opostos será criado um contraste forte de cores se opondo uma a outra).

Figura 01: Representação do círculo cromático.

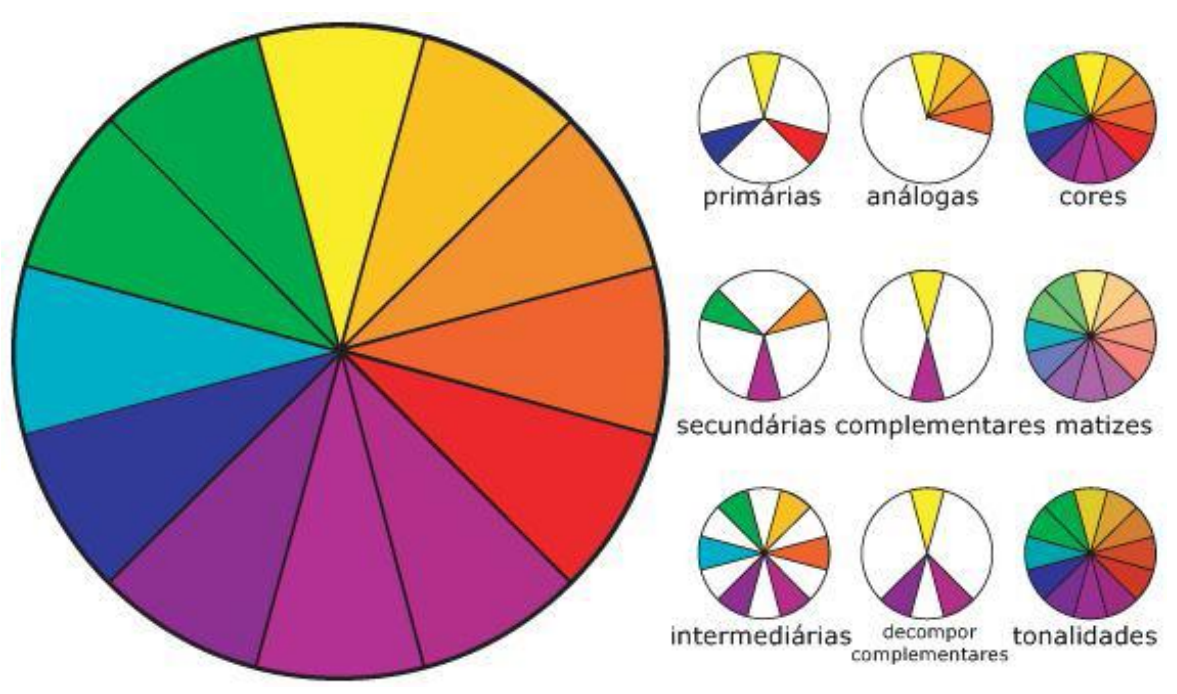

Fonte: http://www.dcoracao.com/2010/10/teoria-das-cores-circulo-cromatico.html

Folts et al (2007) explica que "colocar cores contrastantes lado a lado acentuará suas diferenças. As cores contrastantes podem ser complementares - cores opostas umas ás outras no circulo cromático - ou cores quentes em contraste com as frias. Entretanto, usar uma mistura de cores que sejam relacionadas vai criar um imagem harmoniosa e menos impactante. Você também consegue o mesmo resultado fotografando objetos nos quais todas as cores sejam essencialmente a mesma. As imagens monocromáticas usam as cores com muita sutileza e são realçadas pela adição de uma cor isolada, que passa a ser o ponto focal da imagem" (p.222). Folts ressalta que "o contraste de iluminação é apenas um dos fatores que determinam o contraste geral de sua foto final.

Contraste da cena - a diferença em valores entre tons claros e escuros do objeto - também tem seu papel. Por exemplo, um ovo branco fotografado contra um fundo branco terá menos contraste do objeto do que um pedaço de carvão fotografado contra o mesmo fundo branco." (p.163). Hedgecoe (2006) explica que "Diferentes tipos de 
luz produzem cores diferentes, chamadas temperaturas das cores, que são medidas na escala Kelvin. Embora o cérebro possa se ajustar a essas variações, o filme fotográfico não pode.” (p.136). Quando o mesmo autor explica sobre a correção automática de cores, ele diz "As câmeras digitais corrigem automaticamente as diferentes temperaturas de cor...todas as câmeras digitais possuem um sistema automático de balanceamento de branco. A maioria das câmeras digitais também oferece ajustes manuais de balanceamento de branco, permitindo que você determine a filtragem desejada para obter um efeito criativo ou corrigir pressupostos incorretos do sistema automático" (p.125).

Para Hedgecoe (2006) "o balanceamento automático do branco é eficiente em muitas situações, mas, como ocorre com todos os sistemas automáticos, há ocasiões em que ele não alcança os resultados desejados. Às vezes, o balanceamento automático do branco pode corrigir demais a cor (...), outras vezes você pode quere alterar deliberadamente o balanceamento da cor." Para ele "Em muitas situações não é necessário corrigir o balanceamento de cor, mesmo que a filtragem, o filme ou o ajuste não sejam ideais para aquela luz. Em geral, é possível obter um efeito melhor com um balanço de cor "errado". Às vezes o balanceamento errado da cor ajuda a composição como um todo. Uma cena a Luz de vela é um bom exemplo: o balanceamento correto de cor eliminaria completamente os tons laranjas da imagem. " HEDGECOE (p.142) Hedgecoe (2006) afirma que "entre todos os elementos da fotografia, a cor é de longe o mais poderoso, e, portanto o que deve ser usado com o máximo cuidado. Porque, ao contrario dos outros elementos, a cor desperta fortes reações emocionais.

Preferimos certas cores a outras. As cores intensas imediatamente chamam nossa atenção, ao passo que as opacas se fundem com o segundo plano. Algumas cores tem efeito relaxante; outras nos excitam e estimulam. A relação que temos com cores se intensificam quando elas aparecem juntas, ou porque se complementam, ou porque se chocam. São essas reações à cor que os fotógrafos devem levar em consideração em suas fotos coloridas.” (P.232).

\section{Método}

\section{Camarão na Moranga}

Para esta fotografia foi utilizada uma câmera Canon EOS-1D Mark II com uma lente 24-70mm, f 2.8 Também foi utilizado duas fontes de luz: um Speedlight com uma sombrinha a direita do prato a um ângulo de $45^{\circ}$ e outro speedlight direto à esquerda do prato num angulo de $90^{\circ}$. 


\section{Galinha D'Angola}

Foi utilizada uma câmera Canon EOS-1D Mark II com uma lente 24-70mm, f 2.8. Utilizei um speedlight com uma sombrinha num angulo $45^{\circ}$ a direita do prarto e um speedlight direto de contra a esquerda do prato para dar um contraste e ter uma luz mais dura.

\section{Pão Alemão}

Foi utilizada uma Canon EOS-1D Mark II com uma lente 24-70mm, f 2.8. .As fontes de luz utilizadas foram 2 flash speedlight,um deles ficou a uma angulação de $45^{\circ}$ a direita do prato com uma sombrinha branca e o outro ficou a esquerda da mesa, jogado direto no pão para dar uma luz mais dura e forte.

\section{Doce Fino de Morango}

Os equipamentos utilizados na imagem foram: uma câmera Canon 60D com uma lente 50mm f1.8. Um Flash Report 160 da Atek e um rebatedor circular prata.

\section{Risoto de Camarão na Tábua}

Utilizou-se uma câmera Canon 60D com uma lente 50mm f1.8. As luzer utilizadas foram um flash report 160 da atek com um haze de $0,70 \mathrm{~cm}$ x $0,70 \mathrm{~cm}$. Utilizei também um rebatedor circula prata.

\section{Considerações Finais}

\section{Fotografia 01: Camarão na Moranga}

A foto foi produzida no Grazie! Restaurante. A composição da cena foi feita com um vaso de flor e uma taça de vinho com a garrafa para recriar um ambiente agradável que o restaurante oferece. O verde do vaso de flor faz harmonia análoga com os detalhes verdes do prato e contrasta com o laranja do camarão, moranga e a luz de fundo.

A luz laranja ao fundo vem do balcão do bar e por sorte sua cor ajudou a harmonizar com o prato, tendo apenas o trabalho de posicionar o prato numa altura que fosse possível aproveitar essa luz na cena. O resultado foi uma imagem cheia de cor e contraste, que sugere um jantar romântico e agradável. 


\section{Fotografia 01: Camarão Na Moranga}

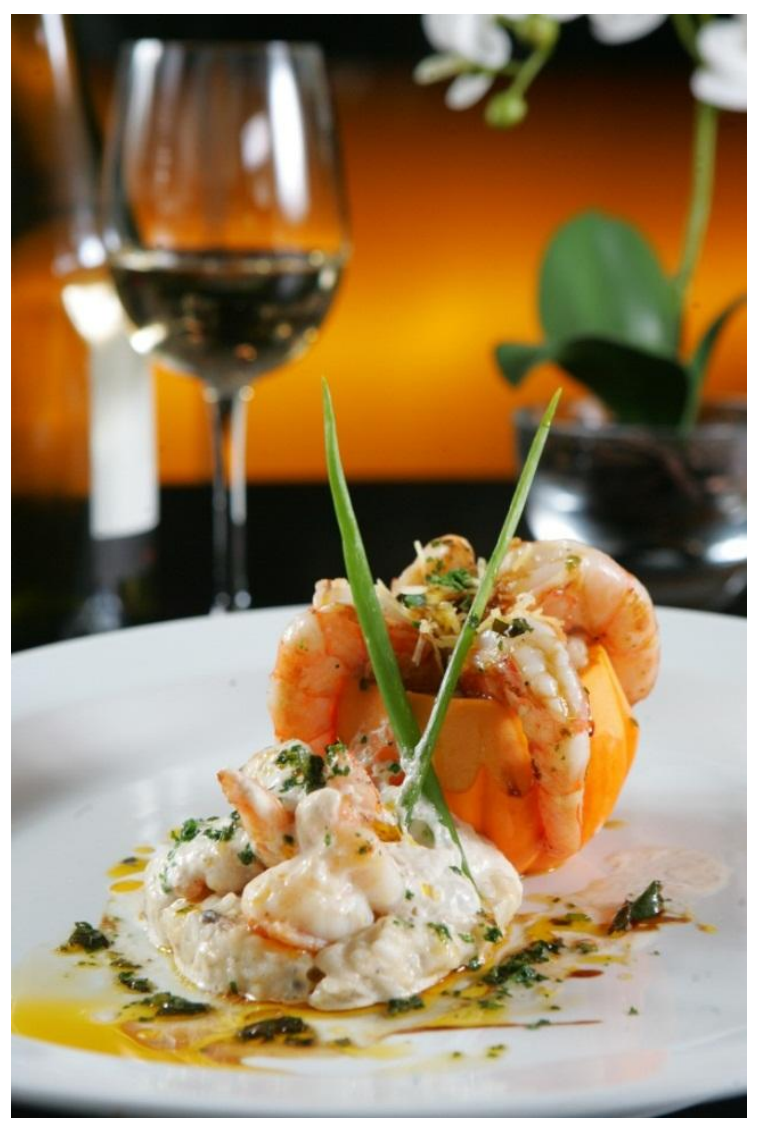

Canon EOS-1D Mark II, 70mm, f/7.1, 1/125, Iso 500

\section{Fotografia 02: Galinha D'Angola}

O prato foi preparado no Hotel Gran Marquise como sugestão para jantar na noite de Natal. Chegando ao local observei que tinha uma enorme árvore de natal na recepção do hotel. Decidi então posicionar o prato de forma que pudesse aproveitar a iluminação da arvore e compor a cena com as luzes de fundo. Inicialmente as fotos não teriam essas luzes de fundo, mas como tive a possibilidade de utiliza-la na foto, improvisamos e agreguei mais informação a foto com a iluminação que vinha da arvore. Foi preciso aumentar o ISO para aproveitar a luz da árvore, já que o ambiente não era bem iluminado. Eu poderia controlar a iluminação do prato como queria, porém a árvore de fundo só seria possível utilizá-la se aumentasse o ISO mesmo que isso comprometesse a qualidade final da imagem devido ao ruído. Sobre as cores, o laranja do frango harmoniza com as luzes da arvore ao fundo e contrasta com o verde dos elementos no prato. A taça de vinho tinto foi utilizada para compor a cena sugerindo o tradicional vinho da noite de natal. 
Fotografia 02: Galinha D'Angola

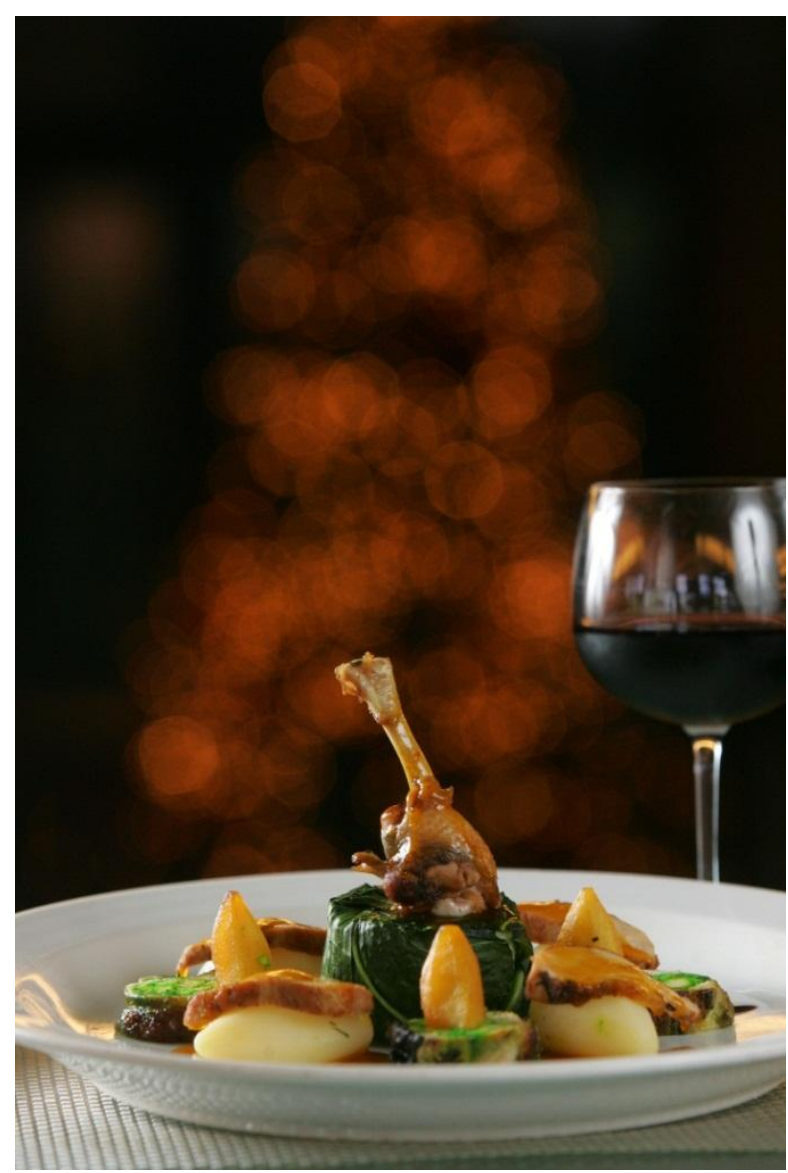

Canon EOS-1D Mark II, 125mm, f/5, 1/80, Iso 640

\section{Fotografia 03: Pão Alemao}

A foto foi feita na sala de estar do próprio produtor dos Paes. A ideia era montar uma cena bem natural dos Paes e ao fundo acompanhamentos do pão: tomate cereja, queijo e presunto defumado. Cortar fatias do pão foi essencial para dar naturalidade a cena como se a mesa estivesse pronta para ser servida. O pano verde foi utilizado para contrastar com o pão amarelado e os elementos de acompanhamento, como o tomate cereja e o presunto. A decisão de colocar o pão sobre a tabua de madeira deixou um ar rústico a foto, que era a intencional. Depois de produzida a foto, senti a falta de uma faca tipo serra, que certamente teria acrescentado mais naturalidade e informação a cena se colocada próxima as fatias do pão.

A cena ficou interessante, com os elementos e o pano, tabua, mesa de madeira e o pão fatiado deram um tom rústico a cena, que reproduzia a forma como o pão era produzido, em pequena escala, artesanalmente num sitio fora da cidade por um produtor alemão. Porem o elemento faca ficou faltando a cena, que poderia ter deixado a imagem mais atraente. 


\section{Fotografia 03: Pão Alemão}

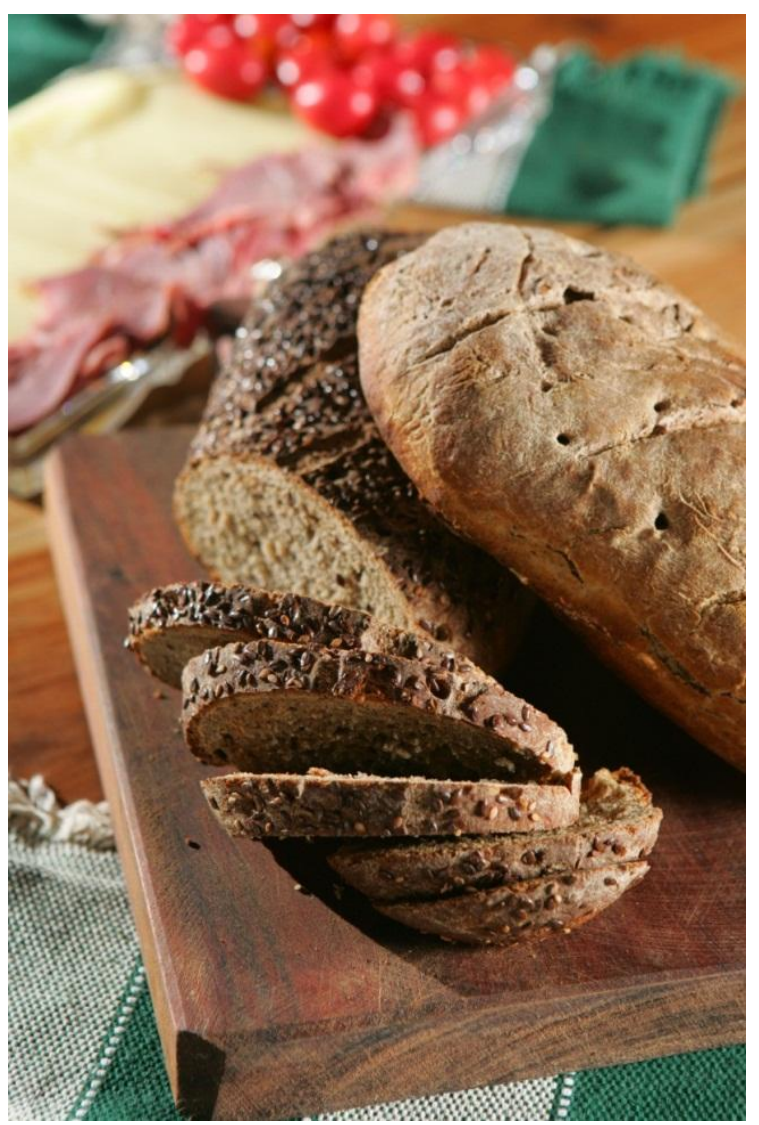

Canon EOS-1D Mark II, 70mm, f/5, 1/125, Iso 400

\section{Fotografia 04: Doce Fino de Morango}

O prato foi preparado para um cliente que queria criar imagens conceito para seu novo site. O Buffet tem fabricação própria e queria nas fotografias conceitos demonstrar as habilidades e capacidade dos seus chef de cozinha em fabricar peças sofisticadas. A escolha do louça, o desenho do alimento escolhido, auxiliam para dar a ideia desejada. No morando coloquei um pequena quantidade de azeite para dar viscosidade ao alimento e um brilho maior quando a flash refletisse no alimento. $\mathrm{O}$ fundo escolhido foi o laranja para relacionar com o vermelho do morando e a o amarelo da calda. 


\section{Fotografia 04: Doce Fino de Morango}

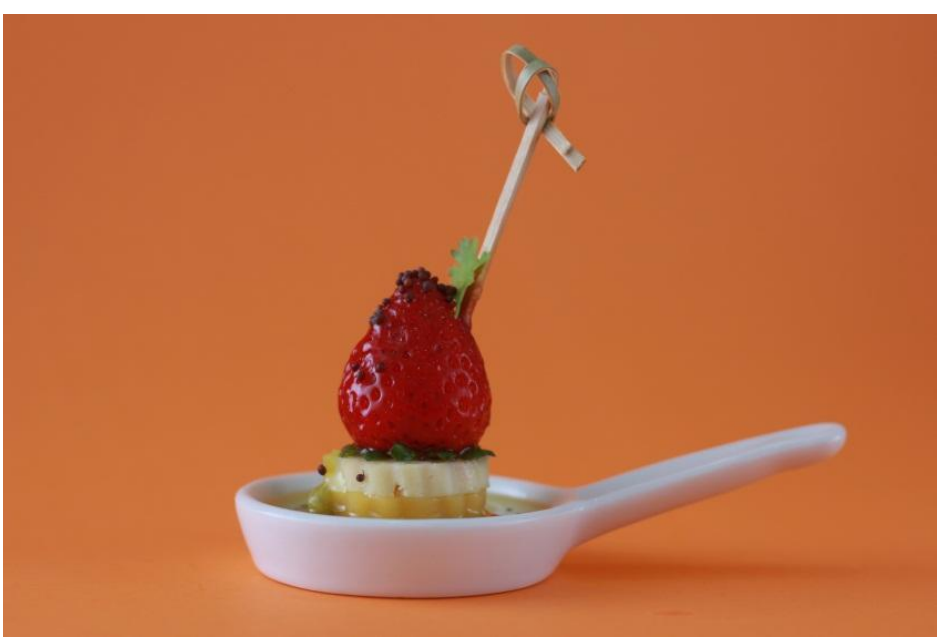

Canon 60D, 50mm, f/3.5, 1/125, Iso 125

\section{Fotografia 05: Risoto De Camarão na Tábua}

O haze usou-se rebatido numa parede branca localizado a esquerda do prato a aproximadamente 1 metro de distância. Já o rebatedor posicionei do lado direito do prato para suavizar algumas sombras. A composição da mesa foi feita para deixar a cena natural. O coentro foi colocado na cena para dar um contraste na cor e o dosador de sal grosso derramando para contribuir na naturalidade da foto. O fundo preto foi escolhido para deixar neutro além de dar um ar de sofisticação a arrumação do prato. Para mostrar todos os elementos nítidos e como todos estão quase no mesmo plano, a abertura do diafragma utilizada foi de f 7.1, já suficiente para me dar a nitidez desejada na imagem. No pós-produção, o tratamento de todas as imagens foi basicamente o mesmo, utilizando o programa Adobe Photoshop CS3, ajustando contraste, níveis, nitidez e saturação .

Fotografia 05: Risoto de Camarão na Tábua

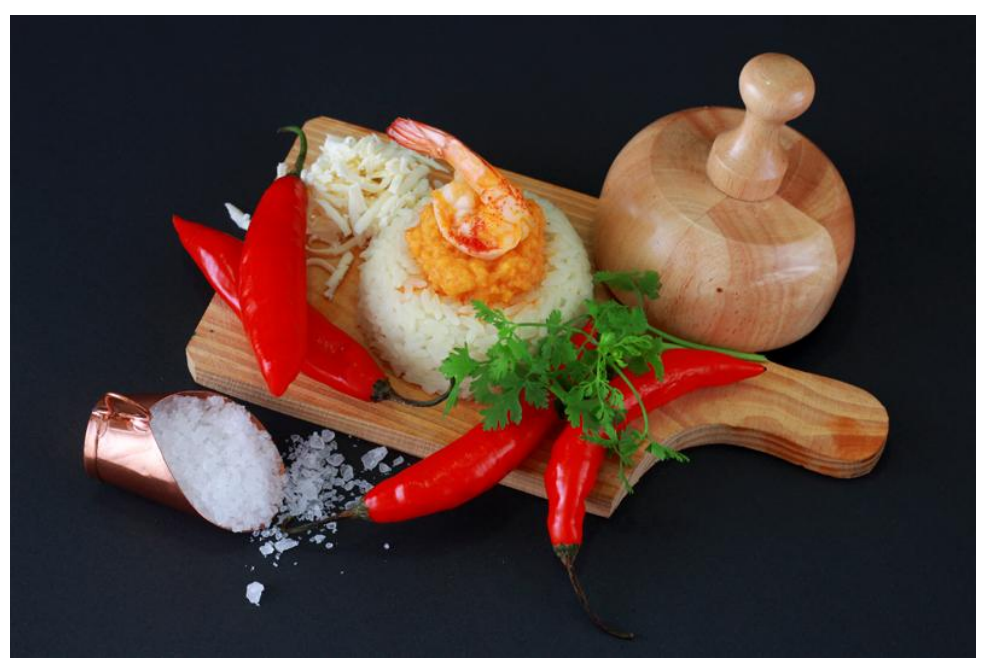

Canon 60D, 50mm, 1/50, f/7.1, ISO-500 


\section{Referências}

FARINA, Modesto. Psicodinâmica das cores em comunicação / Modesto Farina: revisor científico Jairo Pires Leal; diretor de arte Heliodoro Teixeira Bastos. São Paulo, Edgar Blücher, $1^{\circ}$ edição 1982 - 2º edição 1986.

FOLTS, James A et al. Manual de fotografia ; revisão técnica Denise Camargo - são Paulo: Ed. Thomson Learning, 2007.

FREEMAN, Michael, Grande manual de fotografia, 2ª edição em língua portuguesa, Lisboa ,2001.

GUIMARÃES, Luciano. A cor como informação: a construção biofísica, linguística e cultural da simbologia das cores. São Paulo. Ed. Annablume, 2000. 150p.

HEDGECOE, John et al. O novo manual de fotografia: guia completo para todos os formatos / tradução de assef Nagib kfouri e alexandre Roberto de carvalho. - 2ª edição. - São Paulo: editora SENAC são Paulo, 2006.

Recebido: 07/02/2015

Aceito: $19 / 02 / 2015$ 